All determinations were done according to Gorsky and Dietz ${ }^{3}$ in the Institut Pasteur, Lyons, using a Perkin-Elmer atomic absorption spectrometer model 3030 with an HGA 600 graphite furnace and a Zeeman background correction system. The intra-assay and interassay coefficients of variation were less than $5 \%$.

Aluminium concentration in Mérieux albumin was the lowest $(1.03(\mathrm{SD} 0.13) \mu \mathrm{mol} / \mathrm{l})$. In the other products aluminium content showed a wide disparity ranging from $4 \cdot 1$ to $1301 \mu \mathrm{mol} / 1$ depending on batch and manufacturer.

The source of aluminium contamination in albumin solutions is not yet known. It might originate from the extraction of filters and filter aids used to clarify fractions obtained during the manufacturing process, or from containers, glass, or bottle caps. ${ }^{4}$

Albumin is usually separated from other plasma components by Cohn's or Cohn's modified method. Our product is the only one to be fractionated from placental blood, however, not from plasma. This led us to improve the purification procedure by including one more step in the fractionation process: an ion exchange on diethylaminoethanol dextran and adsorption chromatography on diethylaminoethanol derivatives of silica beads. ${ }^{5}$ Before chromatography aluminium was found at a low concentration ranging between 0.41 and $1.68 \mu \mathrm{mol} / \mathrm{l}$. It was no longer detectable after chromatography, although the protein concentration was nearly 10 times the initial value. The reappearance of a low but detectable aluminium concentration in the final albumin sample was explained by the fourfold increase in protein concentration caused by the last ultrafiltration step.

To prevent aluminium overloading, especially in patients with impaired renal function, the albumin solutions should contain very low amounts of aluminium. Chromatography is a useful additional step to the classical fractionation process to remove aluminium contamination.

R EL HABIB

Institut Mérieux

69348 Lyon Cedex 07

France

J P EYGONNET

1 Maher ER, Brown EA, Curtis JR, Phillips ME, Sampson B Accumulation of aluminium in chronic renal failure due to administration of albumin replacement solutions. $\mathrm{Br} \mathrm{Med} \mathcal{J}$ 1985;292:306

2 Milliner DS, Shinaberger JH, Shuman RN, Coburn JW. Inadvertent aluminium administration during plasma Inadvertent aluminium administration during plasma replacement solutions. N Engl f Med 1985;312:165-7.

3 Gorsky JE, Dietz AA. Determination of aluminium in biological samples by atomic absorption spectrophotometry with a graphite furnace. Clin Chem 1978;24:1485-90.

4 Milliner DS, Feldman F, Shinaberger JH, Colburn JW. Aluminium contamination of albumin replacement solutions. NEnglf Med 1985;312:1390.

5 Tayot JL, Tardy M, Gattel P. Ion exchange and affinity chromatography on silica derivatives. In: Curling J, ed. chromats of plas on silica derivatives. In: Curling J, ed. Methods of plasma

\section{Use of ${ }^{9 m}$ Tc labelled sucralfate in detection} of bowel disease

SIR,-It is unfortunate, but on chemical grounds not unexpected, that ${ }^{99 m} \mathrm{Tc}$ sucralfate failed to function as a diagnostically useful marker for lower gut ulceration when used by $\mathrm{Mr}$ A George and colleagues (5 September, p 578) after preparative catharsis with Picolax. An explanation of their observations may well involve the following.

While the main action of sucralfate is to bind to gastric mucosa and to granulation tissue in ulcer bases, some of it dissociates in aqueous solution at low $\mathrm{pH}$ to form sucrose sulphate and release aluminium ions. ${ }^{1}$ As this material moves down- wards in the intestine with a concomitant rise in pH above 5 aluminium hydroxide will be freshly precipitated in a highly surface active form, so that it will readily bind ions such as phosphate. ${ }^{2}$ At least some of this aluminium hydroxide is likely to remain in association with the parent ${ }^{99 m}$ Tc labelled sucralfate. Luminal "hot spots" thus probably indicate the occurrence of what is well known in another context as phosphate binding by aluminium based antacids. Such phosphate binding is used therapeutically in the treatment of chronic renal failure. The characteristic pattern of the " $699 \mathrm{~m}$ Tc sucralfate filled" colon with haustral pattern outlined ${ }^{3}$ may well reflect the luminal distribution of ${ }^{99 m} \mathrm{Tc}$ marked phosphate.

In the more acidic conditions of the stomach and proximal duodenum no such aluminium hydroxide would be formed, and no binding of phosphate would occur ( $\mathrm{R}$ W Cargill et al, unpublished observations), so that ${ }^{99 m}$ Tc labelled sucralfate acts as a reliable marker for ulceration only in the acid secreting stomach. Beyond the pylorus in the lower intestine it is likely to be more a marker for phosphate in the lumen than for ulceration of the gut. George et al may be correct in suggesting that ${ }^{99 m} \mathrm{Tc}$ sucralfate is not reliable as an ulcer marker in the lower gut unless the $\mathrm{pH}$ conditions there are rendered exceptionally lowthat is, $\mathrm{pH}<4$. Preparation with lactulose or mannitol is unlikely to achieve these values. Even then, however, phosphate binding to the lumina contents must greatly reduce its specificity and reliability.

Uptake of the labelled sucralfate by faecal material has already been implicated as causing confusion in this proposed diagnostic technique (31 October, $p$ 1134). We propose that this uptake comes about through phosphate binding.

\section{W K STEWART}

Department of Medicine,

Ninewells Hospital and Medical School, Dundee DD1 9SY

Department of Molecular and Life Sciences, Dundee College of Technology, Dundee DD1 1HG

1 Nagashima R, Yoshida N. Sucralfate, a basic aluminium salt of sucrose sulphate, I. Drug Res 1979;29:1668-76.

2 Larson EA, Ash SR, White JL, Hem SL. Phosphate bindin gels: balancing phosphate adsorption and aluminium toxicity. Kidney Int 1986;29:1131-5.

3 Dawson DJ, Khan AN, Miller V, Radcliffe JF, Shreeve DR. Detection of inflammatory bowel disease in adults and children: evaluation of a new isotopic technique. $\mathrm{Br} \mathrm{Med} \mathcal{F}$ 1985;291:1227-30.

\section{Fetal and neonatal mortality}

SIR,-The results of the survey from Curaçao (10 October, $p$ 894) show that babies of low birth weight are the most important factor in determining the neonatal mortality rate of a population. As Dr H I J Wildschut and others have pointed out, large reductions in perinatal mortality will come as a result of long term political and socioeconomic development, ${ }^{12}$ but it is nihilistic to assume that more immediate measures cannot improve the situation. The number of babies born in hospital implies that most Curaçao mothers have ready access to antenatal care and if this is adequate then in the short term it may be wiser to examine aspects of neonatal care.

There are two areas worthy of further consideration-asphyxia and infection.

Despite adequate antepartum and intrapartum care there will be babies who require resuscitation. ${ }^{3}$ Prompt and adequate neonatal resuscitation can prevent damage due to postnatal delay in achieving normal cardiac output, blood gas pressures, and respiratory function. Hypoxic-ischaemic encephal- opathy and other adverse effects of asphyxia may not always be fully recognised among concomitant problems in preterm or low birthweight infants but undoubtedly contribute to overall mortality. ${ }^{45}$

Infection - an important problem in neonatal care world wide-is relegated to the miscellaneous category. In developing countries mortality from neonatal sepsis has been estimated at 80 per 1000. In Papua New Guinea, where there is a comparable situation, offering secondary care and with a similar neonatal mortality, ${ }^{7}$ neonatal sepsis accounts for $25 \%$ of all deaths in secondary care nurseries. ${ }^{8}$ As with asphyxia, for preterm or low birthweight infants septicaemia may be the terminal insult. The initial description of the Curaçao study mentions blood culture analysis, but the results of these investigations are not apparent. If the organisms cultured from the lung are a true reflection of the invasive septicaemias experienced by newborn infants in Curaçao then this may need further investigation. Geographical and temporal variations of pathogens responsible for neonatal sepsis have been well described but the predominance of Pseudomonas spp and Klebsiella spp must be worrying. The high numbers of placentas with chorioamnionitis might also implicate antepartum or intrapartum infection as a major factor in the deaths of some of the preterm babies, and data from Addis Ababa suggested that ascending amnionitis can be a major cause of perinatal death.$^{10}$ Even in the tertiary care nurseries of developed countries there are still high death rates of 20 to $75 \%$ in treated cases ${ }^{11}$ so that preventive measures may be more fruitful than early diagnosis and treatment.

There are short term measures aimed at preventing asphyxia and infection which might help to decrease neonatal mortality in the population described.

Goroka Base Hospital,

Papua New Guinea

DONALD F MACGREgOR

1 Rinke CM. Infant mortality and the low birth weight infant. JAMA 1985;253:826.

2 Alberman E. Prospects for better perinatal health. Lancet 1980;i:189-92.

3 Russel G Lydon Y, Tunstall M. Antenatal prediction of neonatal asphyxia. Anaesthesia 1975;30:118.

4 Cabal LA, Devaskar U, Siassi B, Hodgman JE, Emmanouilides G. Cardiogenic shock associated with perinatal asphyxia in preterm infants. I Pediatr 1980;96:705-10.

5 Brown JK. Infants damaged during birth. In: Hull D, ed. Recent advances in paediatrics. Edinburgh: Churchill Livingstone, 1986:57.

6 Ebrahim GJ. Perinatal priorities in developing countries. In Ebrahim GJ, ed. Paediatric practice in developing countries. London: Macmillan Press, 1981:195-201.

7 Grant JP. Basic indicators. In: UNICEF. The state of the world's children. Oxford: Oxford University Press, 1986

8 Vince JD. Neonatal care in perspective: results of neonatal care at Port Moresby. Papua New Guinea Medical foumal 1987, 30:127-34.

9 Siegel JD, McCracken GM. Sepsis neonatorum. $N$ Engl f Med 1981;304:642-7.

10 Naeye RL, Tafari N, Judge D, Gilmour D, Marboe C. Amniotic fluid infections in an African city. J Pediatr 1977;90:965-70.

\section{HIV antigenaemia and prognosis}

SIR,-Dr Court Pedersen and colleagues and Dr F de Wolf and colleagues (5 September, p 567, 569) confirm that the persistence of human immunodeficiency virus (HIV) antigen in infected homosexual patients indicates a poor prognosis and even increases the risk of asymptomatic patients developing the acquired immune deficiency syndrome (AIDS). A similar tendency might be surmised for intravenous drug abusers, and we report here the preliminary results of a prospective study of intravenous drug abusers from Barcelona, which combined specific HIV antigen and antibody detection with an assessment of clinical state. The presence of HIV antigen was analysed ${ }^{1}$ in 